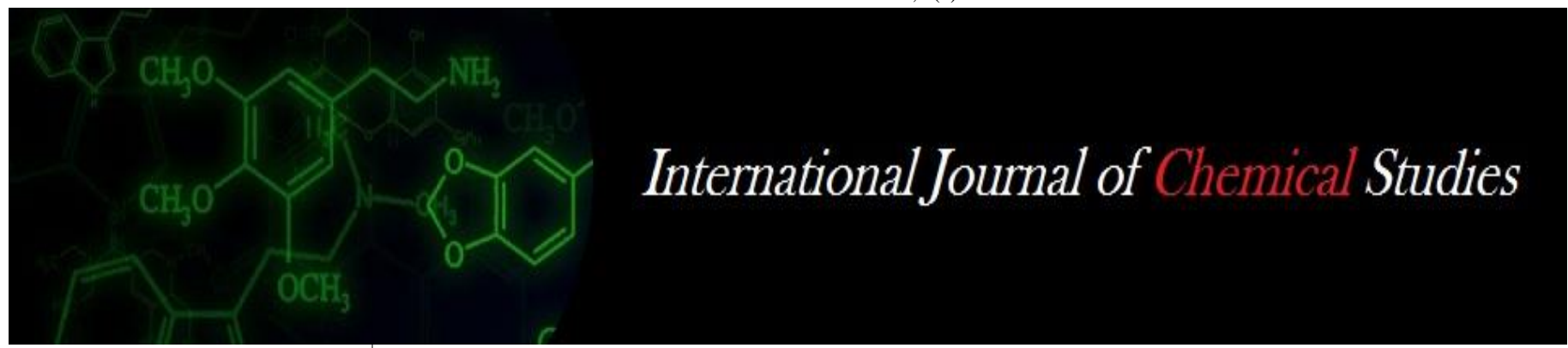

P-ISSN: 2349-8528

E-ISSN: 2321-4902

IJCS 2020; 8(1): 1117-1123

(C) 2020 IJCS

Received: 10-11-2019

Accepted: 12-12-2019

MK Ghosal

Professor, Department of Farm Machinery and Power, Odisha University of Agriculture and Technology, Bhubaneswar, Odisha, India

Paritosh Sarangi Ex- M.Tech Student, Department of Farm Machinery and Power, Odisha University of Agriculture and Technology, Bhubaneswar, Odisha, India

Corresponding Author: MK Ghosal

Professor, Department of Farm Machinery and Power, Odisha University of Agriculture and Technology, Bhubaneswar, Odisha, India

\section{Studies on some physical properties of groundnut of TMV-2 variety}

\section{MK Ghosal and Paritosh Sarangi}

DOI: https://doi.org/10.22271/chemi.2020.v8.i10.8399

\begin{abstract}
Some physical properties of pod $(8.23 \%$ moisture content) and kernel $(11.46 \%$ moisture content) of groundnut variety TMV2, widely cultivated in Odisha, revealed that the average pod length, width, thickness and 1000-unit mass were 24.32, 11.13, $11.56 \mathrm{~mm}$; and $798.23 \mathrm{~g}$, while the corresponding values for kernel were $10.32,6.86,6.72 \mathrm{~mm}$; and $294.89 \mathrm{~g}$ respectively. The sphericity of pod was $21.33 \%$ less than the kernel and surface area was $72 \%$ more than that of the kernel. Bulk densities of pod and kernels were 255.66 and $547.03 \mathrm{~kg} \mathrm{~m}^{-3}$, the corresponding true densities were 470.06 and $950.33 \mathrm{~kg}$ $\mathrm{m}^{-3}$ and corresponding porosities were 44.36 and $41.72 \%$ respectively. The angle of repose of pod and kernel were 30.99 and $39.61^{0}$ respectively. The coefficient of friction was highest for GI sheet (0.43) followed by plywood (0.31) and least in case of plastic sheet (0.22). The data are useful not only for engineer in designing planting and post-harvest equipment but also for food scientists, food processor and plant breeders.
\end{abstract}

Keywords: Groundnut, physical properties, oil seed, moisture content, TMV2

\section{Introduction}

The information regarding the physical properties of any biological material such as fruits, seeds, grain etc. are very much necessary for developing appropriate planting and post-harvest machinery. Designing a machine, without taking into consideration of the relevant data on the engineering/physical properties like geometric properties (length, width, thickness, arithmetic mean diameter, geometric mean diameter, sphericity and surface area), gravimetric properties (including unit mass, 1000 grain mass, true volume, true density, bulk density and porosity) and frictional properties (angle of repose and static coefficient of friction) results into its working inefficiency causing the post-harvest losses of the crop and ultimately reduction in the economic benefits for the growers. The knowledge on the above aspects not only therefore helps the engineer engaged in developing mostly post-harvest machinery of the crops for the operations like threshing, decortication, cleaning, grading, drying, storage, transportation and oil extraction, but also act as a ready reckoner for food scientists, food processors, plant breeders etc. especially for processing, nutritional quality, preservation and seeding purposes. One such problem is being faced among the cultivators in Odisha, India, by the use of commercially available power $(1 \mathrm{hp})$ operated cast iron sheller bar type groundnut decorticator. The above unit has been developed and marketed by the manufacturers without referring to the relevant physical properties pertaining to the decortication and winnowing operations of the most widely prevailing variety of groundnut i.e. TMV 2. Studies on the performance of the above decorticator showed low shelling efficiency and high kernel breakages (Paritosh and Ghosal, 2016) ${ }^{[21]}$. As a result, farmers are to go for the traditional hand shelling method resulting into low income from the broken kernels and poor quality seeds for use in sowing purpose. Hence, it needs modification for reducing post-harvest losses and thus to enhance productivity. Besides decortication, the study of the physical properties of the same variety of groundnut provides information for designing the suitable planting and other post-harvesting machinery. The size (such as length, breadth, thickness, arithmetic mean diameter and geometric mean diameter) and shape (sphericity and aspect ratio) are important in designing, separating, harvesting, shelling, sizing and grading of the bio-materials. Bulk density, true density and thousand grain mass are used in determining the size of storage bins and also affects the structural loads. 
The angle of repose is important in designing storage and transporting structures. Porosity (calculated from bulk density and true density) and surface area affect the resistance to air flow through the bed formed due to bulk of the materials and data on them are necessary in designing the drying process. Fruit part fraction gives an overall idea about the composition of kernel and shell which affect the oil yield of the product. The ability of any grain, fruit or seed to either roll or slide depends on the aspect ratio as well as sphericity. Similarly, in drying process, moisture content is an important parameter to be taken into consideration. Though the literatures regarding agronomic practices and cultivation details of the variety TMV 2 and its oil characteristics are known, no study has been undertaken on its physical properties. Since the size and shape of many local varieties of the same crop are different from each other, thus the aim of the study is to investigate some physical properties of the widely cultivated groundnut of cv. TMV 2 in Odisha. Decortication is one of the important operations in groundnut cultivation and groundnut is a major oil seed crop grown in the state of Odisha $\left(17^{0} 31^{\prime} \mathrm{N}\right.$ to $20^{0}$ $31^{\prime} \mathrm{N}$ latitude and $81^{\circ} 31^{\prime} \mathrm{E}$ to $87^{\circ} 30^{\prime} \mathrm{E}$ longitude) where climate is most suitable for groundnut cultivation during Kharif and Rabi season (Anonymous 2015) ${ }^{[1]}$. There is therefore, a need to develop a suitable decorticator as a modification to the existing $1 \mathrm{hp}$ power operated commercially available groundnut decorticator by considering some of the physical properties of the pod and kernel in order improve its shelling performances. The present study is thus undertaken to find out the engineering/physical properties of the pod and kernel of TMV 2 variety groundnut whose characteristics features have been mentioned in Table. 1. The parameters studied include moisture content, oil content, size, 1000-unit mass, fruit part fraction, arithmetic mean diameter, geometric mean diameter, sphericity, aspect ratio, surface area, bulk density, porosity, angle of repose and coefficient of friction.

Table 1: Characteristics of TMV-2 variety Groundnut

\begin{tabular}{|l|c|c|c|c|c|c|c|c|}
\hline Variety & Habit & $\begin{array}{c}\text { Duration } \\
\text { (in Days) }\end{array}$ & $\begin{array}{c}\text { Avg. yield } \\
(\mathbf{q} / \text { ha) }\end{array}$ & $\begin{array}{c}\text { Rainfall } \\
(\mathbf{m m})\end{array}$ & \multicolumn{2}{|c|}{ Sowing time } & Soil type & Special character \\
\cline { 5 - 6 } TMV 2 & Bunchy & 105 & 12 & 522 & May-June & $\begin{array}{c}\text { January-March \& } \\
\text { May-July }\end{array}$ & $\begin{array}{c}\text { Sandy loam, } \\
\text { loamy sand }\end{array}$ & $\begin{array}{c}\text { Seed salmon in colour. Spheroidal in shape, } \\
\text { moderate resistant to early \& late spot. }\end{array}$ \\
\hline
\end{tabular}

\section{Materials and Methods Sample}

The groundnut pod was procured from State Seed Corporation, Odisha, Bhubaneswar for the study. The study was conducted in Odisha University of Agriculture and Technology. The sample was selected, cleaned manually and pooled together to obtain approximately $10 \mathrm{~kg}$ of pods. It was ensured that the pods were free of dirt, broken ones, immature pods and other foreign materials. The pods were kept in the room conditions $\left(27-32{ }^{0} \mathrm{C}, 75-80 \% \mathrm{RH}\right)$ for two days to obtain the equilibrium moisture. The pods were decorticated carefully and manually to get the whole kernel. The shells and kernels were separated manually for analysis.

\section{Moisture and oil content}

The moisture content of the pod and kernel were determined separately using American Society of Agricultural Engineers (ASAE) standard method (ASAE, 1989) ${ }^{[3]}$. Weighed amount of the samples were dried in a hot air oven at $105 \pm 2{ }^{\circ} \mathrm{C}$ and weighed every time after cooling the samples in desiccator till constant weight was obtained. Weight loss on drying to a final constant weight was recorded as moisture content of the material. The moisture content (dry basis) of the pod and kernel was calculated using the following equation,

Moisture content $(\%)=($ Initial weight of sample-final weight of sample) / (dry weight of sample) x 100.

The oil content was determined using AOAC method (1984) [2]. The dried sample from the moisture content determination was extracted in a Soxhlet-type extractor with petroleum ether (boiling point $60-80{ }^{\circ} \mathrm{C}$ ). The extract was dried for 30 minutes at $90{ }^{\circ} \mathrm{C}$ in a rotary evaporator, cooled and the residual oil weighed. Reported values of pod and kernel are the mean of the five observations.

\section{Physical Characteristics of Pod and Kernel}

The pod and kernel materials were divided into 5 lots each and 20 samples were selected at random from each lot of pod and kernel to obtain 100 samples each for conducting the experiments.

\section{Physical Dimensions}

The physical dimensions are the length, equatorial diameter (width) and breadth (thickness). The length $(L)$ refers to the major diameter while the breadth $(T)$ is the minor diameter of the pod/kernel. The intermediate diameter is the equatorial diameter or width $(W)$. Knowledge of these dimensions is useful in determining aperture sizes in the design of pod/kernel handling equipment (Omobuwajo et al., 1999) ${ }^{[17]}$. The length $(L)$, width $(W)$ and thickness $(T)$ of groundnut pod were measured using a vernier slide caliper (Fig. 1) with an accurate reading of $0.02 \mathrm{~mm}$. The average diameter was calculated by using the arithmetic mean and geometer mean of the three axial dimensions. The arithmetic mean diameter, $D_{a}$, and geometric mean diameter, $D_{g}$, of the groundnut pod and kernel were calculated by using the following relationships (Dash et al., 2008 and Davies 2009) ${ }^{[7,8]}$.

$$
\mathrm{D}_{\mathrm{a}}=(\mathrm{L}+\mathrm{W}+\mathrm{T}) /(3) \text { and } \mathrm{D}_{\mathrm{g}}=(\mathrm{LWT})^{1 / 3}
$$

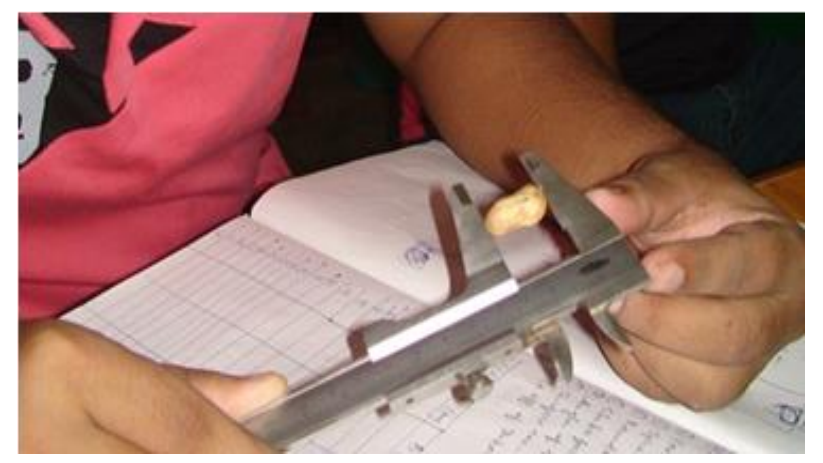

Fig 1: Measurement of length, width and thickness of groundnut

\section{Thousand-unit weight determination}

A 1000-unit mass refers to the mass of thousand pods/kernels. The mass and density characteristics of the pods are quite useful in estimating product yield and machine throughput of equipment (Omobuwajo et al., 1999) ${ }^{[17]}$. Pod weight affects pod flow and in turn, influences the design of hoppers for pods in processing equipment (Jayan and Kumar, 2004) ${ }^{[12]}$. 
One-thousand-unit weight was determined by means of a digital electronic balance having an accuracy of $0.001 \mathrm{~g}$. To evaluate the 1000-unit weight, 20 randomly selected pods from each moisture level were averaged.

\section{Sphericity}

The flowability characteristic of the pod and kernel is influenced by the sphericity, such that movement of nonspherical seeds under gravity is mostly slow (Omobuwajo et

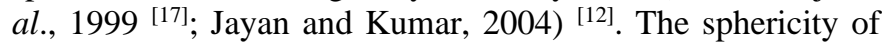
groundnut pod/kernel was calculated by using the following relationship (Mohsenin, 1986) ${ }^{[15]}$ :

$\Phi=(\mathrm{LWT})^{1 / 3} /(\mathrm{L})$

\section{Aspect ratio}

The aspect ratio, $R_{a}$ was calculated by applying the following relationships given by (Maduako et al 2006 and Ogunjimi et al 2002) ${ }^{[14,16]}$ :

$\mathrm{R}_{\mathrm{a}}=(\mathrm{W} / \mathrm{L}) \times 100$

\section{Surface area}

The surface area was determined by coating the surface of the pod with aluminum foil. The surface edge of the aluminum foil was traced out with a very sharp thin pencil on a graph paper as shown in fig. 2. The surface area was measured by counting the number of squares within the traced marks (Adejumo and Abayomi 2012) ${ }^{[4]}$.

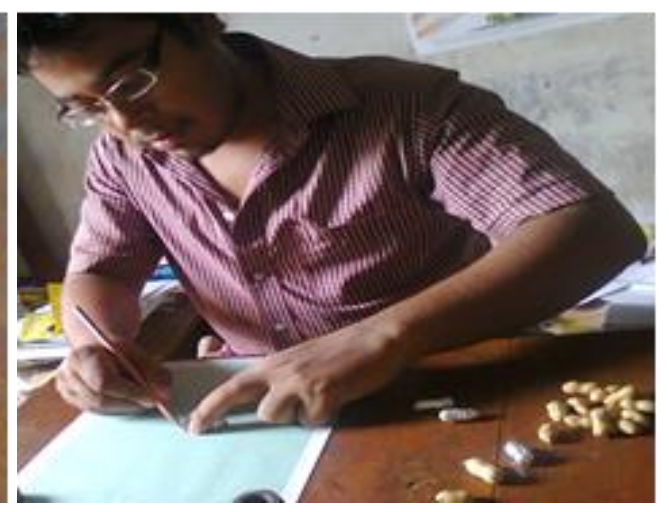

Fig 2: Surface area determination by surface coating method

\section{Bulk density}

Bulk density is the density of the material when packed or stacked in bulk while solid density is the density of the material excluding any interior pores that are filled with air (Sahin and Sumnu, 2006) ${ }^{[20]}$. Materials with large pore spaces among them have lower bulk densities compared with those having small pore spaces. The bulk density was determined by filling a cylindrical container of $500 \mathrm{ml}$ volume with the $\mathrm{pod} / \mathrm{kernel}$ from a height of $150 \mathrm{~mm}$ at a constant rate and then weighing the contents (Gupta and Das, 1997; Garnayak et al., 2008) [11, 10]. No separate manual compaction of pods/kernels was done. The bulk density was calculated from the mass of the bulk material divided by the volume containing the mass. (Fig. 3).
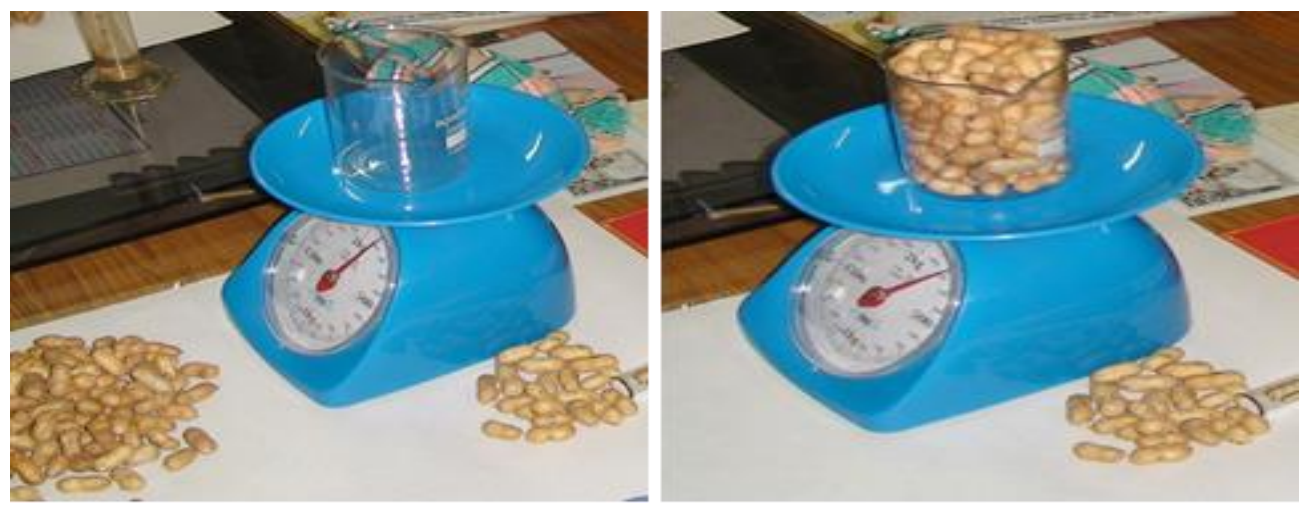

Fig 3: Measurement of bulk density

\section{True density}

The true density is defined as the ratio between the weight of groundnut pod/kernel to the true volume of the $\mathrm{pod} / \mathrm{kernel}$, determined using the toluene $\left(\mathrm{C}_{7} \mathrm{H}_{8}\right)$ displacement method. Toluene was used in place of water, because, it is absorbed by pods to a lesser extent. The volume of toluene displaced was found by immersing a weighted quantity of pod/kernel in the measured toluene (Sacilik et al., 2003; Garnayak et al., 2008) $[19,10]$. True density determination is shown in fig. 4 .

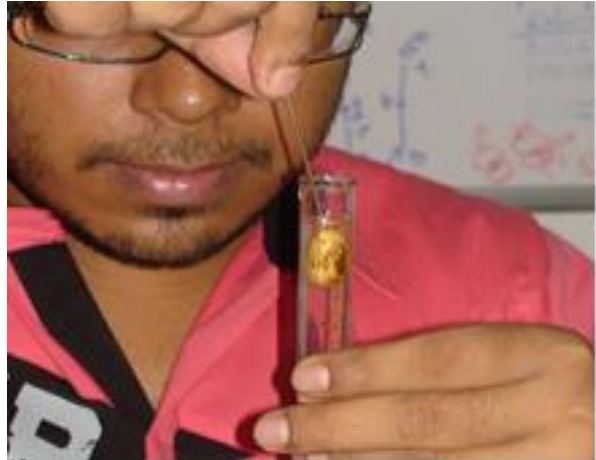

Fig 4: True density determination 


\section{Porosity}

Porosity is usually needed in air flow and heat flow situations like winnowing, cleaning, drying, storage, etc. (Garnayak et al., 2008; Pradhan et al., 2009) ${ }^{[10,18]}$. According to Mohsenin (1986) ${ }^{[15]}$, porosity $(\%)$ is the parameter indicating the amount of pores in the bulk materials. It is calculated from the bulk and true density using the following equation.

$\epsilon(\%)=\left[\left(\rho_{t}-\rho_{b}\right) / \rho_{t}\right] \times 100 ;$ where $\rho_{b}=$ Bulk density; $\rho_{t}=$ True density

\section{Angle of repose}

Angle of repose is also a very important physical property of pod/kernel, useful for the design of processing, storage and conveying systems of agricultural materials. When the grains or seeds are smooth and rounded, the angle of repose is low. Very fine and sticky materials have high angle of repose due to high friction among them (Sahin and Sumnu, 2006; Sirisomboon et al., 2007) ${ }^{[20,23]}$.

The arrangement for determining the angle of repose for the present study consists of a square box of side $84 \mathrm{~mm}$ and height $80 \mathrm{~mm}$ (Paritosh 2013) ${ }^{[22]}$. It consists of a circular platform of diameter $80 \mathrm{~mm}$ inside it. An opening is made at the bottom of the box, below the circular platform to allow for the free fall of pod/kernel. The whole unit was placed at a height of $300 \mathrm{~mm}$. One wall of the box is transparent and it consists of a scale fixed vertically keeping it leveled to the circular platform. Its opposite wall is a mirror so that we can see the pile formed on the platform and take the observations from the mirror avoiding parallax. Fig. 5 shows the photograph of the set up for determination of angle of repose. In the beginning, the box was filled with the pods/kernels keeping the bottom closed. Then, on opening the bottom, the pods/kernels were allowed to fall freely. They formed a pile on the circular platform and the height of the pile was taken by the scale from the image formed at the mirror. This process was repeated for twenty times and using the equation (Karababa 2006) ${ }^{[13]}$ i.e. $\tan \theta=2 H / D$; where $H=$ Height of pile (cone) formed and $D=$ Diameter of formed pile (cone), the angle of repose $\theta$ was calculated.

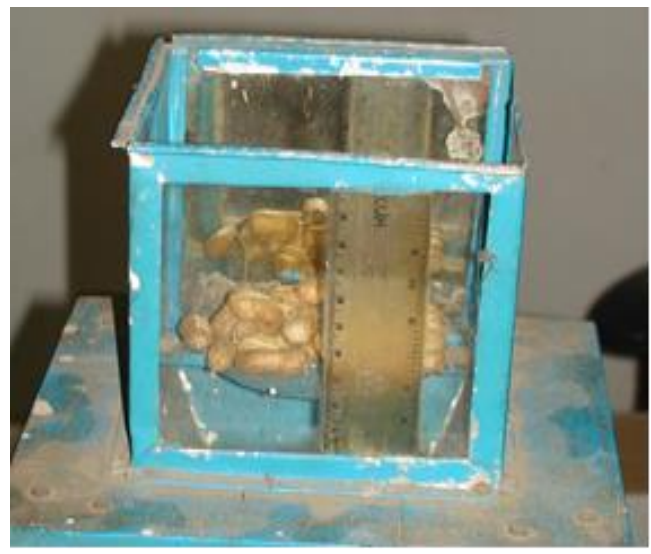

Fig 5: Determination of angle of repose

\section{Coefficient of static friction}

The coefficient of static friction for any biological material is determined by the force capable to initiate the movement. It depends on the type and nature of the materials or surfaces in contact. The data on coefficient of friction are important for hoppers and conveying units used in the decorticator. Static coefficient of friction of the pod/kernel was determined with respect to galvanized iron (GI) sheet, plastic and plywood, available easily and cheaply. A four sided plywood container with dimensions of $200 \mathrm{~mm} \times 80 \mathrm{~mm} \times 50 \mathrm{~mm}$ open at both the top and bottom was filled with the pods/kernels and placed on a plane surface of galvanized iron sheet, plastic and plywood separately for the experiments (Paritosh 2013) ${ }^{[22]}$. The whole structure was placed on a frame of height 1 meter from the ground. A pulley is set at the middle edge of the setup. A thread hooked to the box is provided with the weighing plate. As shown in the figure below, box slides on a plane surface and weighing plate is allowed to hang down by means of a thread moving over the pulley. The box was at the beginning kept at the center position aligning with the pulley so that the box- pulley can be in a straight line. Then, the box was filled with pods/kernels keeping the other end weightless. Weights were added until the box filled with pods/kernel started to slide. Weight of box along with pod/kernel and weight used to make it slide, were calculated. Coefficient of static friction can be determined from, $\mu=F / N$; where $F$ is the applied force and $N$ is the normal load or force. The photograph for measuring of coefficient of static friction is shown in fig. 6.

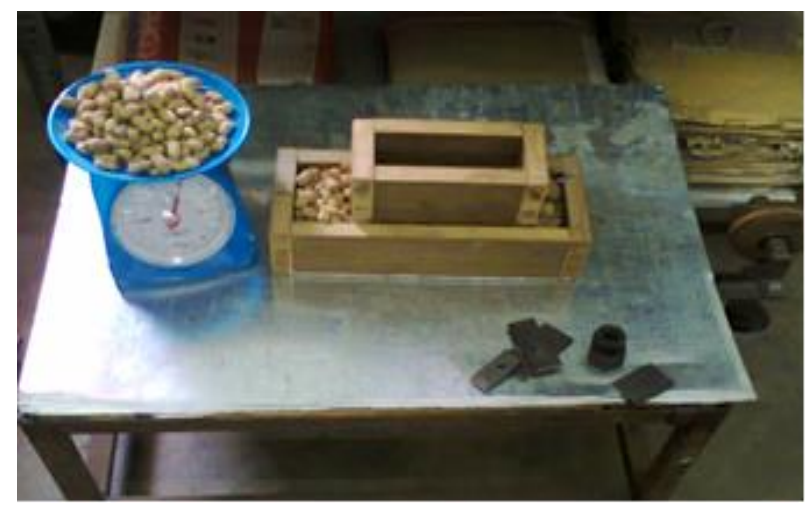

Fig 6: Determination of coefficient of static friction

\section{Results and Discussion \\ Moisture and oil content}

The average moisture and oil content of groundnut pod and kernel are shown in Table 2. The average moisture contents of pod and kernel at the time of experiment were respectively $8.23 \%$ and $11.46 \%$ on dry basis. The kernel contains high moisture compared to the pod. This reflects that drying process needs to be undertaken after the kernel is separated from the pod. The kernel contains $49.31 \%$ oil and shell does 
not contain oil. Hence, oil extraction needs to be done after separation of kernel from the pod. The oil content of TMV2 variety is close to that of the other varieties of groundnut (Balasubramanian et al, 2011) ${ }^{[5]}$.

Table 2: Average moisture and oil content of pod, kernel and shell

\begin{tabular}{|c|c|c|}
\hline \multirow{2}{*}{ Part of the material } & \multicolumn{2}{|c|}{ Mean values } \\
\cline { 2 - 3 } & Moisture content (\% dry basis) & Oil content (\%) \\
\hline Pod (kernel + shell) & $8.23 \pm 0.64$ & $4.46 \pm 5.74$ \\
\hline Kernel & $11.46 \pm 0.47$ & 0 \\
\hline Shell & $5.66 \pm 0.21$ & 3.54 \\
\hline
\end{tabular}

\section{Other Physical Properties}

The average values of determined physical parameters of pod and kernel are shown in Tables 3 and 4 . The pod length, width and thickness were found to be $24.26 \pm 2.21,11.13 \pm 0.63$ and $11.56 \pm 1.04 \mathrm{~mm}$ respectively. Corresponding values for ICGV 00440 are $34.6 \pm 2.4,14.7 \pm 0.9$ and $14.40 \pm 0.8 \mathrm{~mm}$ (Balasubramanian et al, 2011) ${ }^{[5]}$. Hence TMV 2 is smaller in size and accordingly aperture size needs to be considered in developing the appropriate component of post-harvest equipment. The arithmetic and geometric mean diameters for the pod were 15.60 and $14.51 \mathrm{~mm}$ respectively. These values are less than length but more than width and thickness. Shape of the biological material is determined in terms of its sphericity and aspect ratio. The sphericity of pod and kernel of TMV2 were found to be 0.59 and 0.75 respectively. Corresponding values in case of ICGV 00440 for pod and kernel are close to each other i.e. 0.70. As per the investigations by Garnayak et al., $2008^{[10]}$ and Bal and Mishra, 1988, the grain/seed is spherical when the sphericity value is more than 0.70 , otherwise considered to be flat. Hence pod and kernel of TMV2 are considered to be flat and round respectively. The kernel in this case should be treated as an equivalent sphere for the calculation of the surface area. The pod may be treated as a flat for analytical prediction of its drying behavior.

Table 3: Physical properties of groundnut pod (TMV 2) at m.c. $8.23 \%$ (db)

\begin{tabular}{|c|c|c|c|c|c|c|}
\hline Sl. No. & Physical properties & No. of sample & Minimum & Maximum & Mean & Standard deviation \\
\hline 1 & Length $(\mathrm{mm})$ & 100 & 21.21 & 30.82 & 24.32 & 2.21 \\
\hline 2 & Width (mm) & 100 & 10.43 & 12.27 & 11.13 & 0.63 \\
\hline 3 & Thickness (mm) & 100 & 10.15 & 14.41 & 11.56 & 1.04 \\
\hline 4 & 1000 pod mass $(\mathrm{g})$ & 20 & 792.18 & 805.35 & 798.23 & 9.12 \\
\hline 5 & Kernel fraction (\%) & 20 & 69.57 & 78.12 & 73.82 & 6.23 \\
\hline 6 & Shell fraction (\%) & 20 & 21.57 & 29.45 & 26.18 & 4.21 \\
\hline 7 & Arithmetic mean dia $(\mathrm{mm})$ & 100 & 14.02 & 19.05 & 15.60 & 2.32 \\
\hline 8 & Geometric mean dia (mm) & 100 & 13.21 & 17.43 & 14.51 & 3.42 \\
\hline 9 & Sphericity (decimal) & 100 & 0.55 & 0.65 & 0.59 & 0.93 \\
\hline 10 & Surface area $\left(\mathrm{mm}^{2}\right)$ & 100 & 547.02 & 951.06 & 668.15 & 88.79 \\
\hline 11 & Aspect ratio (\%) & 100 & 38.96 & 55.14 & 46.14 & 7.86 \\
\hline 12 & Bulk density $\left(\mathrm{kg} / \mathrm{m}^{3}\right)$ & 20 & 240.03 & 270.11 & 255.66 & 10.40 \\
\hline 13 & True density $\left(\mathrm{kg} / \mathrm{m}^{3}\right)$ & 20 & 290.11 & 650.23 & 470.06 & 78.96 \\
\hline 14 & Porosity (\%) & 20 & 39.28 & 48.42 & 44.36 & 3.62 \\
\hline 15 & Angle of repose $\left(^{\circ}\right)$ & 20 & 27.12 & 34.13 & 30.99 & 3.83 \\
\hline 16 & $\begin{array}{c}\text { Static coefficient of friction (GI sheet) } \\
\text { Plastic } \\
\text { Plywood }\end{array}$ & $\begin{array}{l}20 \\
20 \\
20\end{array}$ & $\begin{array}{l}0.41 \\
0.20 \\
0.28\end{array}$ & $\begin{array}{l}0.44 \\
0.25 \\
0.34\end{array}$ & $\begin{array}{l}0.43 \\
0.22 \\
0.31\end{array}$ & $\begin{array}{l}0.02 \\
0.01 \\
0.02\end{array}$ \\
\hline
\end{tabular}

Table 4: Physical properties of groundnut kernel (TMV 2) at m.c of $11.46 \%$ (d.b)

\begin{tabular}{|c|c|c|c|c|c|c|}
\hline Sl. No. & Physical properties & No. of sample & Minimum & Maximum & Mean & Standard deviation \\
\hline 1 & Length $(\mathrm{mm})$ & 100 & 8.73 & 12.22 & 10.32 & 1.09 \\
\hline 2 & Width (mm) & 100 & 6.16 & 8.73 & 6.86 & 0.91 \\
\hline 3 & Thickness (mm) & 100 & 6.02 & 8.61 & 6.72 & 1.12 \\
\hline 4 & 1000 pod mass $(\mathrm{g})$ & 20 & 284.31 & 304.13 & 294.89 & 6.44 \\
\hline 5 & Arithmetic mean dia (mm) & 100 & 7.31 & 8.64 & 7.91 & 0.54 \\
\hline 6 & Geometric mean dia (mm) & 100 & 7.16 & 8.60 & 7.72 & 0.53 \\
\hline 7 & Sphericity (decimal) & 100 & 0.63 & 0.98 & 0.75 & 0.11 \\
\hline 8 & Surface area $\left(\mathrm{mm}^{2}\right)$ & 100 & 158.04 & 232.12 & 187.04 & 25.10 \\
\hline 9 & Aspect ratio (\%) & 100 & 50.81 & 90.34 & 66.42 & 13.21 \\
\hline 10 & Bulk density $\left(\mathrm{kg} / \mathrm{m}^{3}\right)$ & 20 & 540.06 & 560.34 & 547.03 & 9.57 \\
\hline 11 & True density $\left(\mathrm{kg} / \mathrm{m}^{3}\right)$ & 20 & 930.21 & 990.54 & 950.33 & 23.87 \\
\hline 12 & Porosity (\%) & 20 & 40.23 & 42.63 & 41.72 & 1.22 \\
\hline 13 & Angle of repose $\left(^{\circ}\right)$ & 20 & 34.01 & 45.36 & 39.61 & 3.09 \\
\hline 14 & $\begin{array}{c}\text { Static coefficient of friction (GI sheet) } \\
\text { Plastic } \\
\text { Plywood }\end{array}$ & $\begin{array}{l}20 \\
20 \\
20\end{array}$ & $\begin{array}{l}0.42 \\
0.22 \\
0.28\end{array}$ & $\begin{array}{l}0.47 \\
0.27 \\
0.37\end{array}$ & $\begin{array}{l}0.45 \\
0.24 \\
0.33\end{array}$ & $\begin{array}{l}0.01 \\
0.03 \\
0.02\end{array}$ \\
\hline
\end{tabular}

The mean values of aspect ratio for pod and kernel were found to be $46.14 \%$ and $66.42 \%$ respectively. Aspect ratio defining to the ratio of seed width to length indicates the rolling or sliding over a surface. The sphericity and aspect 
ratio of more than $70 \%$ implied that peanut was more as spherical, and tend to rather roll than slide (Dutta et al., 1988) [9]. The low value of aspect ratio indicated the tendency to slide than to roll. Hence, the pod would slide but kernel would roll as its aspect value $(67 \%)$ is close to the $0.70(70 \%)$. The tendency to either roll or slide is very important in the design of hoppers and dehulling equipment for the seed.

The 1000 pod and kernel mass are 798.23 and $294.89 \mathrm{~g}$ respectively. The corresponding reported values of ICGV 00440 to be 1594 and $784 \mathrm{~g}$ are higher than TMV2 (Balasubramanian et al, 2011) ${ }^{[5]}$.

The surface area of pod is larger than that of kernel by $72 \%$, indicating that mass or energy transfer rate through the surface of the pod might be slower than the rate for kernel.

The mean values of bulk density for pod and kernel were found to be 255.66 and $547.03 \mathrm{~kg} / \mathrm{m}^{3}$ respectively. This indicates that the bulk density of pod is $53 \%$ lower than that of kernel. This indirectly implies that pod needs more space per unit mass than kernels. The true density of pod is less than the density of water $\left(1000 \mathrm{~kg} \mathrm{~m}^{-3}\right)$ due to the air pores between the shell and kernel. The true density of kernel is higher than that of pod. This indicates that the separation of shells from kernel after decortication can be done by blowing air (winnowing). Bulk density is important because it determines the capacity of storage and transport systems.

The mean values of porosity for pod and kernel were found to be $44.36 \%$ and $41.72 \%$ respectively. Since the porosity depends on the bulk as well as true densities, the magnitude of variation in porosity depends on these factors only. The porosity of the bulk of kernel is lower than that of the pod. This also indicates that the aeration of bulk of pod is easier than that of the bulk kernel as porosity determines the resistance to airflow during aeration and drying process.

Adhesion between container wall and material affects the value of angle of repose. The angle of repose of pod is about $27 \%$ lower than that of the kernel. This might have been due to the viscous surface and the least hardness of kernels leading to the highest cohesion among the individual kernels and therefore to the higher angle of repose. This value implies the lowest flow ability of kernels compared to the pods.

The coefficient of friction for pod and kernel was determined with respect to three different structural surfaces. It was found that the coefficient of friction for pod was highest against GI sheet $(0.43)$ followed by plywood $(0.31)$ and least in case of plastic sheet $(0.22)$. The least coefficient of friction may be owing to the smoother and more polished surface of the plastic sheet than the other materials used. The data on the coefficient of friction will be important for designing of storage bins, hoppers and conveyors.

\section{Conclusions}

The studies were undertaken to determine the physical properties of groundnut pod and kernel of variety TMV2, widely cultivated in Odisha. Planting and post-harvest machinery available commercially in the state are generally not designed on the basis of the physical properties of the prevailing variety of groundnut resulting into their poor performances. Hence investigations were carried out and the experiments were conducted when the average moisture contents of pod and kernel were respectively $8.23 \%$ and $11.46 \%$ on dry basis and oil content of kernel was about $49.5 \%$. The physical properties of both pod and kernel including their moisture and oil content, 1000-unit mass, dimensions, arithmetic and geometric mean diameter, pod part fraction, sphericity, aspect ratio, surface area, bulk density, true density, porosity, angle of repose and coefficient of static friction have been determined and reported. The information obtained from the present investigations would enlarge the knowledge about the variety TMV2 and provide useful data for its post-harvest handling not only for decortication purposes but also for other operations of the crop such as planting, sorting, grading, packaging, oil extraction and further industrial processing.

\section{References}

1. Anonymous. Odisha Agricultural Statistics (2013-14), Directorate of Agriculture and Food production, Govt. of Odisha, Bhubaneswar, 2015.

2. AOAC. Association of Official Analytical Chemists. Official Methods of Analysis, $14^{\text {th }}$ ed. Washington, DC, 1984.

3. ASAE. Standards, 36 $6^{\text {th }}$ Ed, S352.1. Moisture measurement-grain and seeds. St. Joseph, Mich: ASAE, 1989.

4. Adejumo OI, Alfa AA, Mohammed A. Physical properties of Kano white variety of Bambara groundnut, Proceedings of the Nigerian Institute of Agricultural Engineers 27:203-210 held between Dec 12 ${ }^{\text {th }}-$ Dec $15^{\text {th }}$, 2005 at Yenegoa, Baelsa State.

5. Balasubramanian S, Sharma R, Sardana V. Studies on Some Engineering Properties of Peanut Pod and Kernel, Journal of Agricultural Engineering, 2011, 48(2).

6. Bal S, Mishra HN. Engineering properties of soybean. Proc. National Seminar Soybean Processing and Utilization in India, Bhopal, M.P., India, 1988, 146-165.

7. Dash AK, Pradhan RC, Das LM, Naik SN. Some physical properties of simarouba fruit and kernel, Int. Agrophysics. 2008; 22:111-116.

8. Davies RM. Some physical properties of groundnut grains, Research Journal of Applied Sciences, Engineering and Technology. 2009; 1(2):10-13.

9. Dutta SK, Neema VK, Bharadwaj RK. Physical properties of gram, J Agric. Engng. Res. 1988; 39:259268.

10. Garnayak DK, Pradhan RC, Naik SN, Bhatnagar N. Moisture-dependent physical properties of jatropha seed (Jatropha curcas L.), Industrial Crops and Products. 2008; 27:123-129.

11. Gupta RK, Das SK. Physical properties of Sunflower seeds, Journal of Agricultural Engineering Research. 1997; 66:1-8.

12. Jayan PR. Kumar VJF. Planter design in relation to the physical properties of seeds, Journal of Tropical Agriculture. 2004; 42(1-2):69-71.

13. Karababa E. Physical properties of popcorn kernel, Journal of Food Engineering. 2006; 72:100-107.

14. Maduako JN, Saidu M, Matthias P, Vanke I. Testing of an engine powered groundnut shelling machine, Journal of Agricultural Engineering and Technology (JAET), 2006; 14:29-37.

15. Mohsenin NN. Physical Properties of Plant and Animal Materials (2nd edn.), Gordon and Breach Science Publishers, New York, USA, 1986.

16. Ogunjimi LAO, Aviara NA, Aregbesola OA. Some physical engineering properties of locust bean seed, Journal of Food Engineering. 2002; 55:95-99.

17. Omobuwajo TO, Akande EA, Sanni LA. Selected physical, mechanical and aerodynamic properties of African breadfruit (Treculia africana) seeds, Journal of Food Engineering. 1999; 40:241-244. 
18. Pradhan RC, Naik SN, Bhatnagar N, Vijay VK. Moisture-dependent physical properties of Jatropha fruit, Industrial Crops and Products. 2009; 29:341-347.

19. Sacilik K, Ozturk R, Keskin R. Some physical properties of hemp grain, Biosystems Engineering. 2003; 86:213-215.

20. Sahin S. Sumnu SG. Physical Properties of Foods, Springer Science + Business Media, New York, USA, 2006.

21. Sarangi Paritosh, Ghosal MK, Mohanty SK, Behera D. Development and performance evaluation of a power operated rubber sheller bar type groundnut decorticatorcum-cleaner, Agricultural Engineering Today, 2016, 40(1).

22. Sarangi Paritosh. Studies on design and operational parameters of groundnut decorticator through rotary mode of operation using bullock power, Unpublished M.Tech. thesis, CAET, OUAT, Bhubaneswar, Odisha, 2013.

23. Sirisomboon $\mathrm{P}$, Kitchaiya $\mathrm{P}$, Pholpho $\mathrm{T}$, Mahuttanyavanitch W. Physical and mechanical properties of Jatropha curcas L. fruits, nuts and kernels, Biosystems Engineering. 2007; 97:201-207.

24. Naderloo L, Alimadani A, Akram P. Javadikia Khanghah HZ. Tillage depth and forward speed effects on draft of three primary tillage implements in clay loam soil, J Food Agriculture Environment. 2009; 7:382-385. 